\title{
Design and Modelling of Thermostatically Controlled Loads as Frequency Controlled Reserve
}

Xu, Zhao; Østergaard, Jacob; Togeby, Mikael; Marcus-Møller, C.

Published in:

IEEE Power Engineering Society General Meeting, 2007.

Link to article, DOI:

10.1109/PES.2007.386014

Publication date:

2007

Document Version

Publisher's PDF, also known as Version of record

Link back to DTU Orbit

Citation (APA):

Xu, Z., Østergaard, J., Togeby, M., \& Marcus-Møller, C. (2007). Design and Modelling of Thermostatically

Controlled Loads as Frequency Controlled Reserve. In IEEE Power Engineering Society General Meeting, 2007. (pp. 1-6). IEEE. https://doi.org/10.1109/PES.2007.386014

\section{General rights}

Copyright and moral rights for the publications made accessible in the public portal are retained by the authors and/or other copyright owners and it is a condition of accessing publications that users recognise and abide by the legal requirements associated with these rights.

- Users may download and print one copy of any publication from the public portal for the purpose of private study or research.

- You may not further distribute the material or use it for any profit-making activity or commercial gain

- You may freely distribute the URL identifying the publication in the public portal 


\title{
Design and Modelling of Thermostatically Controlled Loads as Frequency Controlled Reserve
}

\author{
Z. Xu, Member, IEEE, J. Østergaard, Member IEEE, M. Togeby, C. Marcus-Møller
}

\begin{abstract}
Using demand as frequency controlled reserve (DFR) is beneficial to power systems in many aspects. To study the impacts of this technology on power system operation, control logics and simulation models of relevant loads should be carefully developed. Two advanced control logics for using demand as reserve have been presented in this paper. Electricity loads that are applicable for the technique in practical power systems are analysed. Moreover, a simulation model of thermostatically controlled loads, which can provide frequency activated reserve by controlling their set points according to system frequency, is developed. The developed simulation model is able to represent a variety of aggregated thermostatically controlled loads, such as heaters or refrigerators. Uncertainties including customer behaviours and ambient temperature variation are also modelled. Preliminary simulation results are presented and analysed, which demonstrates the great potentials of the DFR technology.
\end{abstract}

Index Terms-Demand as frequency controlled reserve, thermostatically controlled loads, load modelling

\section{INTRODUCTION}

$\mathbf{I}^{\mathrm{N}}$ $\mathrm{N}$ power system operation, supply and demand balance must be well kept in real time. Traditionally, system operators maintain this balance by utilising reserves mainly from generation side, including extra capacity of on-line generators, back-up generation, imports from interconnected neighbouring systems, and so on. As the last resort, load shedding will only be used by the operator in emergency situations, where the system experiences significant frequency dips.

As a valuable resource for system balance control, the demand actually can play a more active role in this regard, with plenty of potentials to be explored. Since the system frequency is the indicator of supply and demand balance and exists universally in the system, electricity loads can actually

This work was supported by the Danish Public Service Obligation (PSO) research funding program, Project "Demand as Frequency Controlled Reserve", Grant no. 2005-2-6380.

Zhao $\mathrm{Xu}$ is Assistant Professor with Centre for Electric Technology, Ørsted•DTU, Technical University of Denmark, DK-2800 Lyngby, Denmark (email: zx@oersted.dtu.dk)

Jacob Østergaard is Centre Head and Professor with Centre for Electric Technology, Ørsted•DTU, Technical University of Denmark, DK-2800 Lyngby, Denmark (e-mail: joe@oersted.dtu.dk)

Mikael Togeby is Partner and Senior Consultant with Ea Energianalyse A/S, Frederiksholm Kanal 1, 1220 Copenhagen, Denmark (e-mail: mt@eaea.dk)

Catarina Marcus-Møller is with Ea Energianalyse A/S, Frederiksholm Kanal 1, 1220 Copenhagen, Denmark. be quickly turned off, in response to a smaller frequency drop measured locally. This technique of providing fast reserves from frequency responsive loads is termed as demand as frequency controlled reserve (DFR) in this paper.

Various researches have been done in the field of using demand as system reserves. In the past, utilities have operated load management programs for many years before the deregulation [1]. In [2], a market based demand management program using low frequency relay to provide demand side reserve from industrial loads is reported. A similar program is implemented in the New Zealand power system [3]. Both of these two programmes have, however, mainly focused on large size industrial loads. A pilot project using the ComfortChoice technology for controlling air-cons to provide reserve was carried out by the Long Island Power Authority in 2003 [4]. Due to the communication (two way paging) system introduced, the reserve is to be activated with a slower speed, i.e. response within 90 seconds. In [5, 6], the Grid-Friendly ${ }^{\mathrm{TM}}$ technique is developed to provide reserves from domestic appliances such as coffee makers and refrigerators. This technique has presented great potentials in providing fast speed (within seconds or less) and economic reserves from demand sides, which inspires our research in this field.

It should be highlighted that using demand as frequency activated reserve can be fairly beneficial for power system operation in many aspects. From the system operation point of view, the DFR can provide fast speed reserve that can be activated within seconds or less, which is essential for maintaining frequency stability and avoiding large blackouts. Since loads are more distributed than generation resources in powers systems, the reserves from the DFR technique is better distributed when activated, therefore help to alleviate congestions in transmission systems. Furthermore, in light of renewable energy, the implementation of DFR technique will definitely help to further increase the penetration of those fluctuating generations such as wind generation in both largescale or island systems.

Form the electricity market point of view, the implementation of DFR contributes to the full deregulation by allowing demand side participation into Ancillary Service market.

From the society point of view, the DFR technology makes maximal use of available recourse in power systems and provides a cheaper replacement of building extra generation, therefore lowering investments into the power sector. More 
importantly, this will lead to fewer installations of new power plants and further increased penetration of renewable energy, therefore less use of natural resource and less Greenhouse emissions. In general, the DFR technique is environment friendly for sustainable development of human society.

The above analyses are perceived from a broad view, yet to be examined in details through simulation studies. Therefore, simulation models of the DFR loads should be carefully built, which is the main focus of this paper. In power systems, many electricity loads, such as air-cons, heaters, fridges and water treatment plants, can be turned off for a short duration without any bad impacts to the devices or discomforts caused to the customers. Particularly, those thermostatically controlled loads are ideal for frequency controlled reserve, due to their considerable volume and stable profile during the day and year. Moreover, the cyclic on/off characteristics can also give flexibilities for implementation of the DFR technique.

In this paper, a general model for thermostatically controlled loads is developed in DIgSILENT Power factory [7], which is one of the mainstream simulation tools in utilities and research institutions. The developed model can simulate signal or aggregated such loads with DFR function. With this simulation model, further study of DFR's impacts on power system stability and etc can be carried out in our next step research.

The organisation of this paper is as follows: Section II develops two advanced control logics for DFR appliances. The volume of loads that are compatible with the DFR technique in practical power system is also examined herein. Section III focus on modelling of thermostatically controlled loads with DFR capability in DIgSILENT Power Factory. Section IV presents simulation results with analyses. Section $\mathrm{V}$ concludes the paper.

\section{DESIGN of DFR APPLIANCES}

\section{A. Potential of Electricity Loads for the DFR}

In power system there are many loads, from both industrial and domestic sectors, which can be applied with the DFR technique. In this paper, the focus has been made to those home use appliances. Industrial loads will certainly be covered in our future scope.

To identify loads that are compatible with the DFR technique, their characteristics must be analysed. Some guidelines for selecting such loads are summarized [8].

- Firstly, such loads should be able to be disconnected for a short duration without bad influence to the appliance itself and customers;

- Secondly, loads that have stable energy consumption throughout time are more valuable for providing reserve for a longer period;

Given the first guideline, a number of home appliances have been identified, including electricity scape heaters, water heaters, tumble dryers, washing machines, refrigerators, freezers, dishwashers and coffeemakers. In order to quantify the potential in Eastern Denmark, the average electricity consumption of those loads in households is calculated and presented in Fig 1 below. The number of appliances in our calculation is achieved from a Danish study called ELMODEL-bolig, in which the number of apices per household all over Denmark is estimated through a questionnaire survey [8]. The average yearly electricity consumption of a specific appliance is calculated from the average consumption of new and ten year old equipment [8].

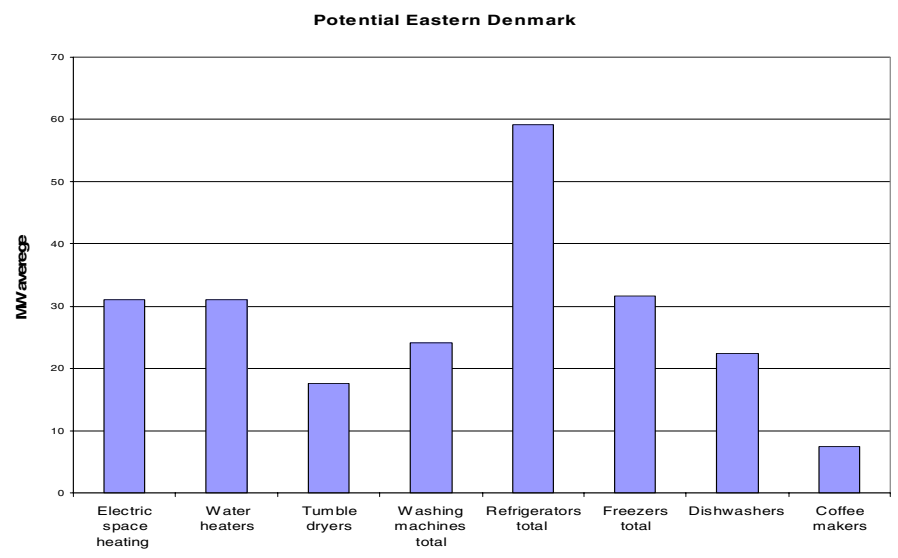

Fig 1 The average electricity consumption of different household appliances in Eastern Denmark

Among those loads, thermostatically controlled appliances, including space and water heaters, refrigerators and freezers, have presented great value, due to their considerable volume and stable profile during the day and year. For example, the refrigerators have the highest electricity consumption of about $60 \mathrm{MW}$ in Figure 1, followed by the freezers and heaters which are all thermostatically controlled.

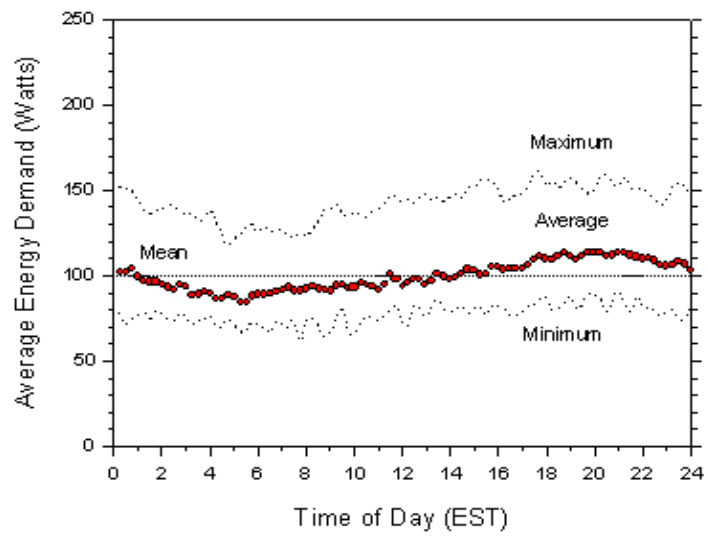

Fig 2 Daily load profile of 10 refrigerators for a year [9]

The load profile of those thermostatically controlled loads is also examined according to the second guideline. Figure 2 shows the daily load curve of 10 refrigerators. The fairly stable load profile well justifies their compatibility for the DFR technique [8]. For the heaters, though the load curve may have seasonal variations, their profile is fairly predictable based on outdoor temperature etc, which has been studied by many researches [10].

Besides the two guidelines, the special cyclic on/off characteristic of the thermostatically controlled appliances 
also provide great flexibility for implementation of the DFR technique. This advantage will be utilised in designing the control logics for the DFR appliances in the following section.

\section{B. DFR Circuits and Design Considerations}

The circuit for a DFR appliance basically consists of three parts as illustrated in Figure 3, including

- Frequency sensor circuit, which continuously measures the frequency of AC voltage from, for example, a wall socket.

- DFR Logic circuit, which fulfils the control criteria of the DFR appliance, including disconnection and reconnection logics.

- Relay circuit to trip and reconnect the appliance to outside power source.

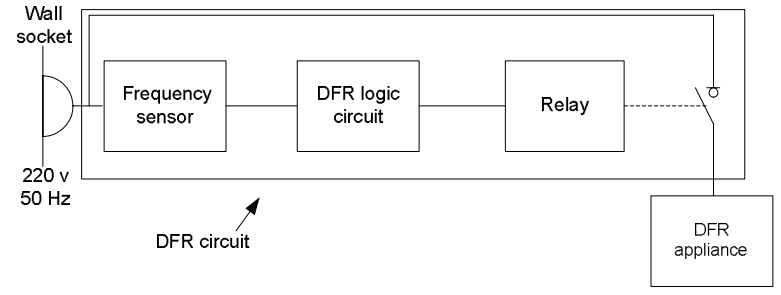

Fig 3 Illustration of a DFR appliance circuit

For the frequency sensor circuit, the measurement should have reasonable speed and accuracy. The fast speed can be archived by using a high sampling rate. A filter can be used to ensure the measurement accuracy. In [5], it has been demonstrated that a frequency sensor circuit with low cost can take less than one second time for frequency measurement with reasonable accuracy. In this paper, two types of advanced DFR control logic I and II have been designed according to different loads.

\section{B.1 DFR Type I}

The type I logic include,

- Tripping criteria of low frequency - to trip loads when, for example, frequency $<49.90 \mathrm{~Hz}$;

- Reconnection criteria - when system frequency recovers to a margin above tripping set point, for example $49.98 \mathrm{~Hz}$;

To select the tripping and reconnection set points appropriately, historical frequency data of a specific power system should be carefully analysed [11]. Currently, the research team is analysing the Nordic system frequency data measured using Phasor Measurement Units (PMUs) with high accuracy and sampling rate $(20 \mathrm{~ms} / \mathrm{sample})$. In addition, the technical specification of the reserves in a power system, at which the DFR is targeted to provide, including activation frequency and timing requirement, should also be taken into account.

In the two criteria above, there are time delays involved. Some of the delays are introduced deliberately due to technical consideration, and some are inevitably due to the frequency measurement process. For example, in order to ensure system frequency fully recover before reconnecting the loads back to the grid, a random delay, say 0 30 seconds, can be applied. With the tripping criteria, the delay in measurement and filtering also exist, but within very short frame [5]. In addition to the low frequency tripping criteria, the type I can also include the fast frequency decay criteria based on the frequency gradient $[5,6]$. Basically, the DFR type 1 logic is applicable to all loads that satisfy the two guidelines in Section II.A.

\section{B.2 DFR Type II}

The DFR type II logic is specially designed for those thermostatically controlled loads with cyclic on/off durations. In this type, in stead of tripping the loads according to system frequency directly, their temperature set points are dynamically controlled according to the frequency [12]. Since there are many such loads in the system, and at each moment they are operating at various states, i.e. their temperature is between lower and upper temperature set points and the power is "on" or "off", this logic will eventually reduce the demand as the type I does. To implement this control logic, a linear relationship between the temperature set points and system frequency can be used. As illustrated in Fig 4, a normal heater has static temperature set points $\boldsymbol{T}_{\text {high }}$ and $\boldsymbol{T}_{\text {low }}$, i.e. the two horizontal (dash) line. With the DFR logic II, the set points become dynamic, varying linearly according to the frequency. Mathematically, this relation is given by,

$$
\begin{aligned}
& T_{\text {high }}=T_{\text {high }}^{\text {normal }}+k f *\left(f-f_{0}\right) \\
& T_{\text {low }}=T_{\text {low }}^{\text {normal }}+k f *\left(f-f_{0}\right)
\end{aligned}
$$

where $T_{\text {high }}^{\text {normal }}$ and $T_{\text {low }}^{\text {normal }}$ are nominal high and low set points, $f_{0}$ is system nominal frequency which is $50 \mathrm{~Hz}$ for the Nordic system, $f$ is actual system frequency, and $k f>0$ is the coefficient of frequency change. For cold loads such as a refrigerator or freezer, this relation becomes [12]

$$
T_{\text {high }}=T_{\text {high }}^{\text {normal }}-k f *\left(f-f_{0}\right)
$$$$
T_{\text {low }}=T_{\text {low }}^{\text {normal }}-k f *\left(f-f_{0}\right)
$$

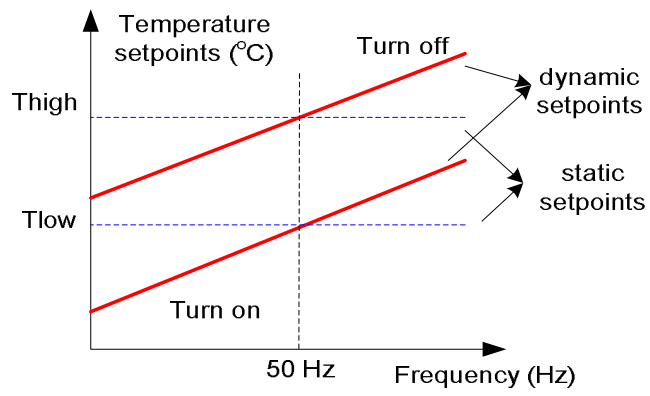

Fig 4 Linearly frequency controlled temperature set points for DFR type II appliances

The collective behaviour of many type II loads is best explained in Fig 5, where dots with up and down arrows represent on and off units. The left side of Fig. 5 shows the situation where the gird frequency is $50 \mathrm{~Hz}$ and totally 10 units are turned on. The right side shows in the next moment the gird frequency goes below $50 \mathrm{~Hz}$, the temperature set points are changed according to Equation (1), resulting in only 7 "on" units left. One additional benefit of the type II DFR is that, the reserve provided is activated proportionally to the frequency drop, assuming that initially those loads are 
uniformly distributed between on and off set points. This property is very attractive since in a practical power system such as the Nordic, the reserves are required to be activated according to system frequency drop as linearly as possible [13]. The simulation model of this type DFR loads is developed in Section III.

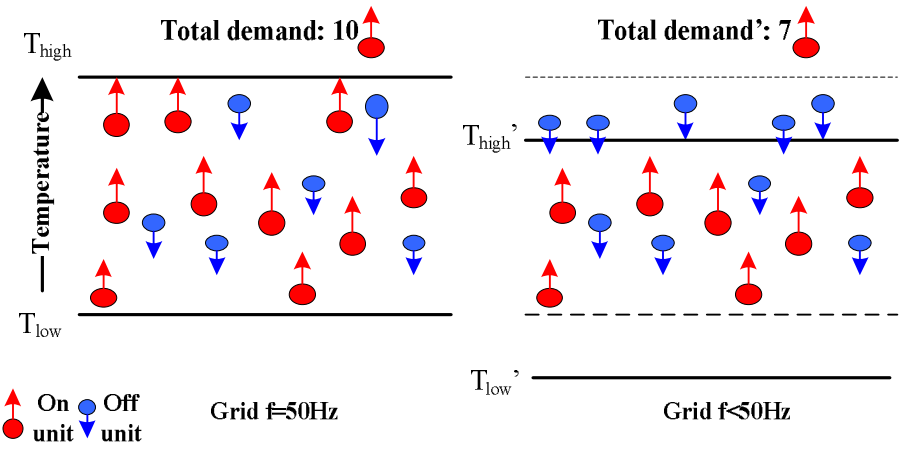

Fig. 5 The collective behaviour of many heaters with frequency controlled temperature set points

\section{MOdELLING OF THERMOSTATICALLY CONTROLLED LOADS WITH DFR FUNCTION}

The thermal dynamics of a space heater is modelled by differentiation equation [14],

$$
C \frac{d T}{d t}+G\left(T-T_{a}\right)=w^{*} P
$$

where $\boldsymbol{C}$ is the heat capacity of the heating mass, $\boldsymbol{G}$ is the thermal conductance between heated and non-heated mass, $\boldsymbol{P}$ is the heater power, $\boldsymbol{T}$ is the temperature of the heated mass, $T_{a}$ is the outdoor temperature, and $\boldsymbol{w}=1$ during unit "on" stage $\left(\boldsymbol{T}<\boldsymbol{T}_{\text {high }}\right)$ and $0\left(\boldsymbol{T}>\boldsymbol{T}_{\text {low }}\right)$ during "off" stage, i.e. the hysteresis is modelled. The Equation (3) only needs small changes to represent the cold loads such as air-cons.

To model customer's influence on the heater's dynamics, an extra term can be introduced. For example, a water heater can be modelled with a term of $\boldsymbol{P}_{\text {water }}$ in Equation (4), which represents customers' water consumption.

$$
C \frac{d T}{d t}+G\left(T-T_{a}\right)+P_{\text {water }}=w * P
$$

Furthermore, those parameters in Equations (3) and (4) including $\boldsymbol{C}, \boldsymbol{G}, \boldsymbol{T}_{\boldsymbol{a}}$ and $\boldsymbol{P}_{\text {water }}$ can be random. For example, $\boldsymbol{P}_{\text {water }}$ is largely customers' habit dependant and is time changing. The ambient temperature $\boldsymbol{T}_{\boldsymbol{a}}$ also changes throughout the day. $\boldsymbol{C}$ and $\boldsymbol{G}$ can change due to random factors, e.g. people enters house, window open, exchange of air or water etc. These uncertainties have been modeled in the simulation model using the characteristic vector (CharVec) in Power Factory [7].

The heater power $\boldsymbol{P}$ in above equations is considered constant in our simulations later on. In fact, the $\boldsymbol{P}$ is resistive for a space or water heater, and is voltage dependent. For loads with compressors such as air-cons and refrigerators, the dynamic nature of $\boldsymbol{P}$ should be modeled [15]. These considerations can be easily added into the simulation model in the future.

For the DFR heater model in this paper, the temperature set points are modeled using Equation (1). To simulate many of those loads, Power Factory models of many heaters are aggregated. Dynamics of each heater is explicitly modeled. For simplification purpose, common temperature set points are used for all heaters in the aggregation model. A common heater power $\boldsymbol{P}$ is also used for individual units, assuming it equals to the average power of the group. In addition, the parameters $\boldsymbol{C}, \boldsymbol{G}, \boldsymbol{T}_{\boldsymbol{a}}$ and $\boldsymbol{P}_{\text {water }}$ are modeled using a common value with time changing characteristics, assuming all heaters have roughly same dynamic nature. The time changing characteristics is to allow these parameters to vary according to the pre-set global simulation time, i.e. the time of a day and year for the simulation to start. The initial temperatures of heaters are assigned as random numbers that are uniformly distributed between $\boldsymbol{T}_{\text {high }}$ and $\boldsymbol{T}_{\boldsymbol{o n}}$. A separate parameter is used to model how much percentage of heaters that are in the "on" cycle. A delay of 0.4 seconds to simulate the frequency measurement process is also included in the model.

\section{Simulation Results AND ANAlyses}

The heater simulation model with the DFR function is shown in Fig. 6. The model is developed using the composite modelling approach in Power Factory [7]. The composite model is connected to a bus which is also connected to a simplified external gird block. To study the impacts of DFR loads on a realistic system, this external grid can be easily replaced by the simulation model of an actual system in the future.

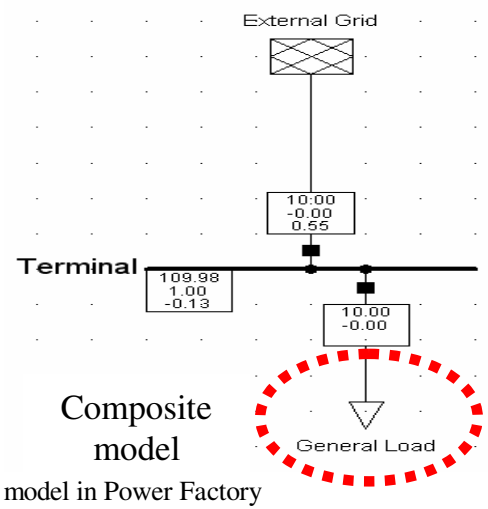

Fig. 6 The heater model in Power Factory

\section{A. Single heater simulation}

The simulation results of a single heater are shown in Fig 7, where the power, heater temperature, the temperature set points, and system frequency are simulated. The temperature set points are set as 18 and 22 degrees, with a dead band of 4 . The heater power $\boldsymbol{P}$ is set as $10 \mathrm{MW}$ and the system nominal frequency is $50 \mathrm{~Hz}$. It is clearly observed in Fig 7 that the frequency drops when the heater is turned on. This results in the heater temperature set points drop according to Equation (1). Consequently, the heater is turned off earlier than if the DFR function is not applied. 

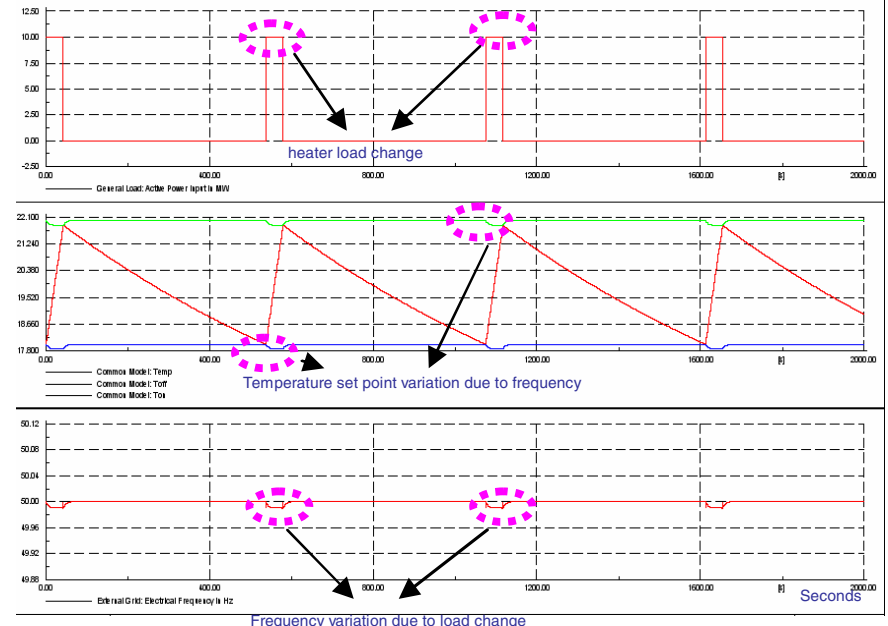

Fig 7 Single heater simulation results of power, temperature and system Frequency

\section{B. Aggregated heater model simulation}

- Case 1: System with the aggregated heater model alone

The aggregation heater model consists of many heater units. In order to build the model as realistic as possible, the heater temperatures are initialized as uniformly distributed random numbers between $\boldsymbol{T}_{\text {high }}$ and $\boldsymbol{T}_{\text {low }}$ in all simulations.
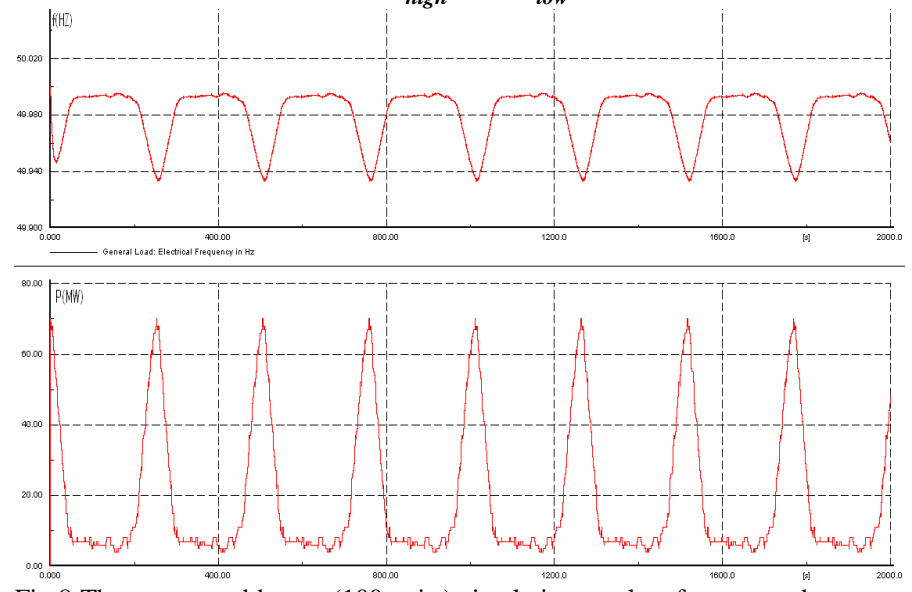

Fig 8 The aggregated heater (100 units) simulation results of power and system frequency without DFR function ( $\mathrm{kf}=0,70 \%$ units initially “on")
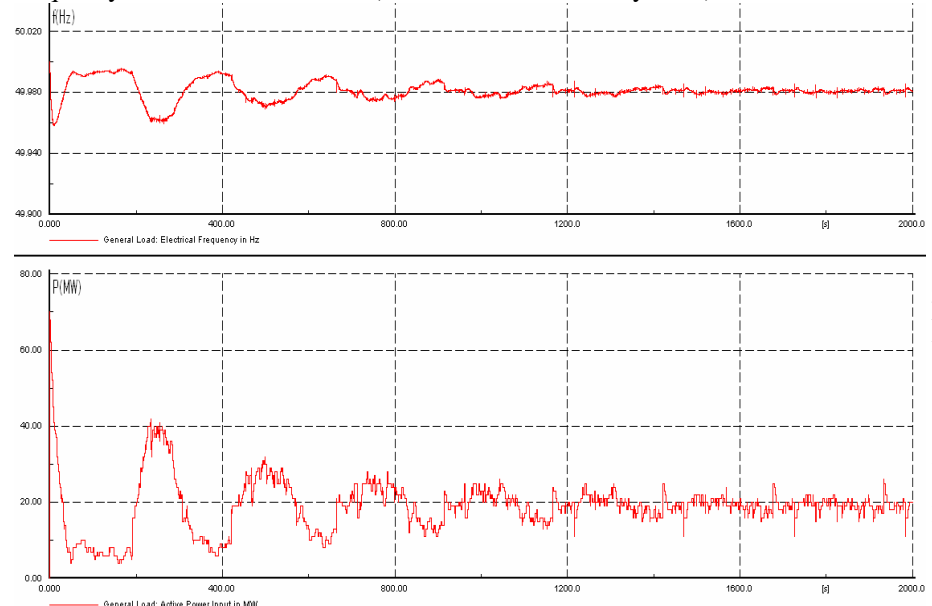

Fig 9 The aggregated heater (100 units) simulation results of power and system frequency with DFR ( $\mathrm{kf}=15,70 \%$ units initially "on")

Similar to the single heater case, the temperature set points are set as 18 and 22 degrees. The heater power $\boldsymbol{P}$ is set as 1
MW, representing the average power of the heater group. Fig 8 shows the simulated system frequency and the power consumption of an aggregation model with 100 units without DFR function for 2000s. The simulation actually takes less than 5 minutes to finish using a standard PC. The results show clearly a cyclic oscillation of power consumption in Fig 8, causing the system frequency oscillates significantly as well. Fig. 9 shows the simulation results of the heater with the DFR type II, where the power consumption oscillates initially, but eventually settles to an approximate constant value of 20 MW. Comparing Figs 8 and 9, the DFR heater shows excellent capability of load shaping, which helps greatly to improve the quality of system frequency.
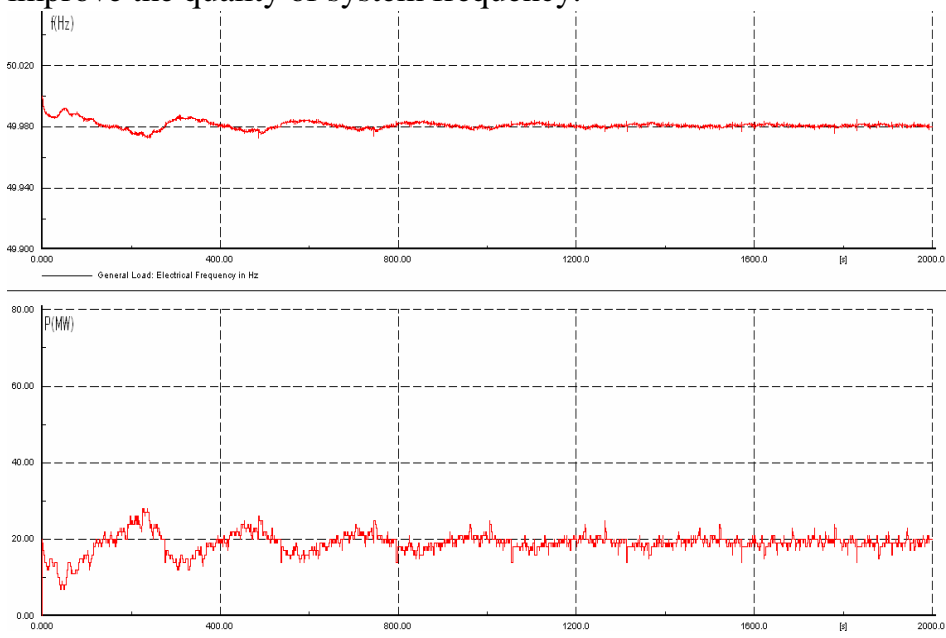

Fig 10 The aggregated heater (100 units) simulation results of power and system frequency with DFR function ( $\mathrm{kf}=15,20 \%$ units nitially "on")

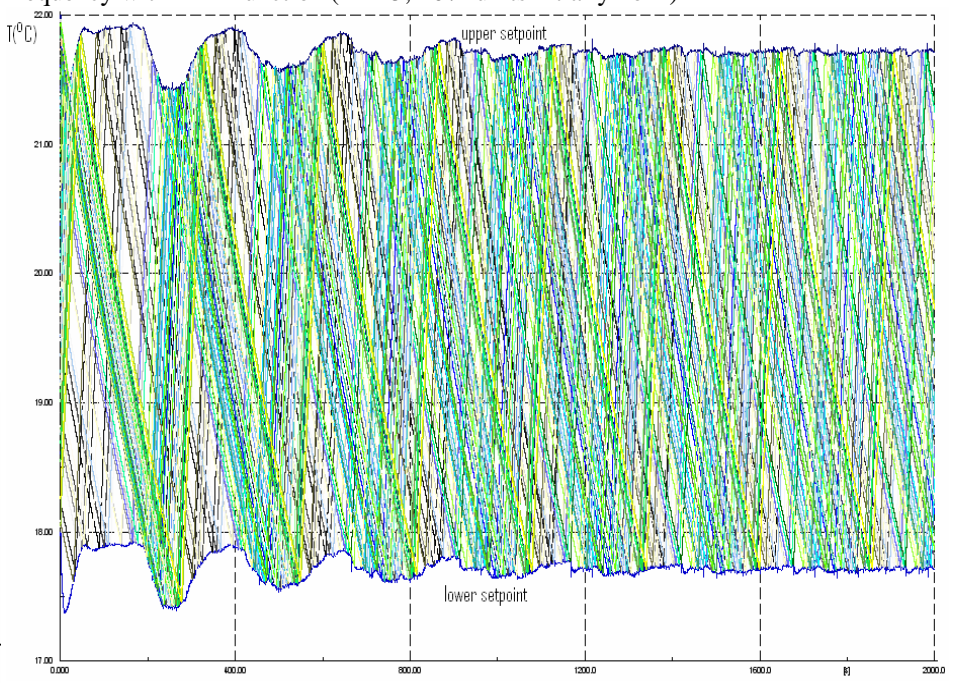

Fig 11 The aggregated heater (100 units) simulation results of heater temperatures with DFR function ( $\mathrm{kf}=15,70 \%$ initially “on")

In both Figs 8 and 9, 70\% of the units are set at the "turn on" cycle initially. Fig. 10 presents the simulation results where $20 \%$ of units are initially on. An interesting observation from Figs 9 and 10 is that the electricity demand of the aggregated heater oscillates in the beginning, and will settle down at about $20 \mathrm{MW}$ after a while. Moreover, the more the heater units are initially "on", the more dramatic oscillations of power consumptions are observed in the beginning. These observations evoke us the idea to build a synthesis model for 
aggregated heaters in the future.

The heater temperatures simulated for the case of Fig 9 is presented in Fig 11, where the temperature set points vary according to the system frequency. Due to this variation, individual heater's working cycle is changed. This explains why the aggregated heater shows the capability of self load shaping and helps to stabilize the system frequency.

\section{- Case 2: System with a load event}

Figs 8 to 11 show the simulation results of the system with the heater model alone, where the frequency variation is caused by the heater only. To further examine this model's capability of providing frequency controlled reserve, the simulation model in Fig. 4 is modified slightly with one extra load module added to the bus. A load event is defined as this additional load is zero initially in the simulation, and will increase to $20 \mathrm{MW}$ at simulation time equal to $1000 \mathrm{~s}$. The parameters used in this case are the same as in Fig. 10. The simulation results are presented in Fig 12, where dash line represents the power consumption of the aggregated heater model and the solid line represents the total demand of the heater plus the extra load. It is clearly shown that, the solid and dash line overlay each other in initially, and the total demand (solid line) increases by $20 \mathrm{MW}$ at $\mathrm{t}=1000$, due to the pre-defined load event. Accordingly, the system frequency drops significantly to about $49.40 \mathrm{~Hz}$. Comparing to Fig 10, the heater power (dash line) clearly decreases from the original approximate $20 \mathrm{MW}$ right after the demand increase. Moreover, the power consumption of the heater model presents slight oscillations after the load event, and will slowly self-adapt to a constant value again as the stimulation going on. From these observations, it therefore can be concluded that the developed heater model is able to provide reserve in response to system frequency variations as designed.
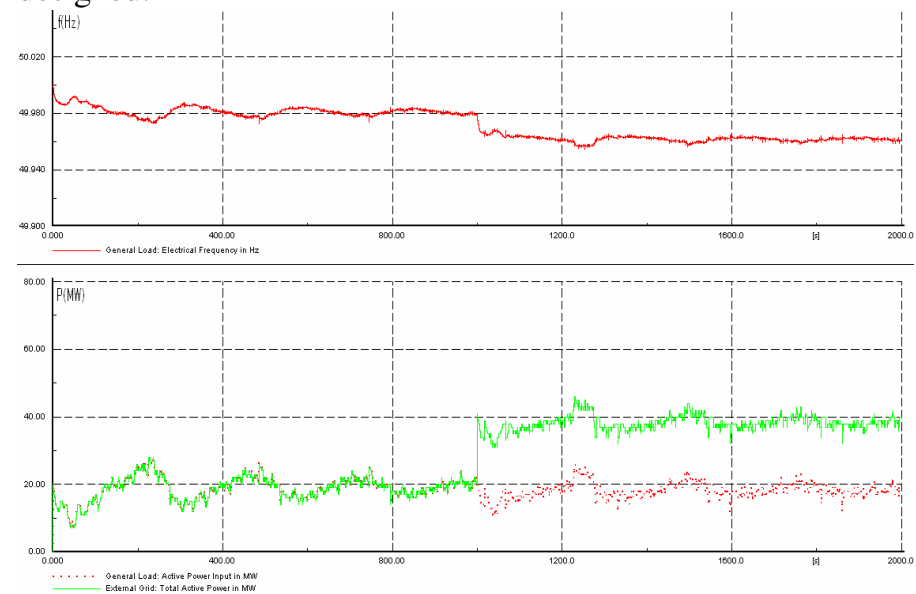

Fig 12 The simulation results (power and frequency) with a load event of 20 MW demand increase at $\mathrm{t}=1000 \mathrm{~s}(\mathrm{kf}=15,20 \%$ initially "on")

\section{CONCLUSION}

With the deregulation of power systems, the potential of demand side participation should be fully explored. In this paper, a technique of using demand for providing frequency controlled reserves (DFR) is presented. Two types of the control logic for such appliance are designed, which can be improved in the future. In addition, the simulation model of thermostatically controlled heaters, which can provide reserve by varying temperature set points according to the system frequency, is developed using DIgSILENT Power Factory. Preliminary simulation results of the developed model demonstrate that this type of DFR loads has excellent capabilities of self load shaping and providing frequency responsive reserve. Further research is underway by the research team, to analyze the frequency data of practical power systems; to refine the developed simulation model and develop a synthesis model from the simulation results; and to simulate such loads with a practical power system, including interconnected and island systems, to study their impacts. The business model and monitoring method for the reserves from this technique will be also investigated.

\section{REFERENCES}

[1] J. D. Kueck. B. J. Kirby, J. Eto, R. H. Staunton, C. Marnay, C. A.Martinez, and C. Goldman, "Load As a Reliability Resource in Restructured Electricity Markets”ORNL/TM2001/97, LBNL-47983. June, 2001. Oak Ridge National Laboratory, Oak Ridge, TN.

[2] M. Bailey, "Provision of frequency responsive power reserve from disconnectable load", IEE Colloquium on Economic Provision Of A Frequency Responsive Power Reserve Service (98/190) 5 Feb. 1998 Page(s):5/1 - 5/5

[3] A. Turner, T. N. Chan and A. N. Gibbs, "A Fast Reacting Power System Load Shedding Management System"., Proceedings of the 9th Conference on the Electric Supply Industry (CEPSI), Hong Kong, 1992

[4] B. J. Kirby, "Spinning reserve provided from Responsive Loads", Oak, Ridge National Laboratory, 2003;

[5] M. Kintner-Meyer, R. Guttromson, D. Oedingen, and S. Lang, "Final Report for California Energy Commission: Smart Load and Grid-Friendly Appliances", prepared by Architecture Energy Corporation and Battelle Memorial Institute, Oct, 2003;

[6] Pacific Northwest GridWise ${ }^{\mathrm{TM}}$ Demonstration, available: http://www.pnl.gov/news/2006/gridwise/gridwise_demo_flier-final.pdf

[7] DIgSILENT, "Power Factory Version 13 .2 User Manual", 2006.

[8] C. Marcus-Moller, "Demand as frequency controlled reserve-Analysis of technology and potentials", student project report, Technical University of Denmark, 2006

[9] Florid Solar Energy Centre website on-line at http://www.fsec.ucf.edu/bldg/pubs/pf300/index.htm

[10] C. Kofod and M. Togeby, "Demand Response offered by households with direct electric heating", proceedings of Demand Response in Energy Markets Conference, Nordic Energy Research, 26 November, 2004.

[11] N. Lu, D. J. Hammerstrom, "Design Considerations for Frequency Responsive Grid FriendlyTM Appliances", PES TD 2005/2006, May 21 24, 2006 Page(s):647 - 652

[12] J. Short, Dynamic Demand on-line at http://www.dynamicdemand.co.uk/

[13] Rekommandasjon for frekvens, tidsavvik, regulérstyrke og reserve Augusti 1996

[14] E. Bompard, E. Carpaneto, G. Chicco, R. Napoli, "Analysis and modelling of thermostatically-controlled loads", Proc. Of the 8th Mediterranean Electrotechnical Conference, 1996, Volume 2, 13-16 May 1996 Page(s):730 - 734 vol.2

[15] IEEE Task Force on Load Representation for Dynamic Performance, "Load representation for dynamic performance analysis [of power systems]", IEEE Transactions on Power Systems, Volume 8, Issue 2, May 1993 Page(s):472 - 482 